Natural Hazards and Earth System Sciences, 5, 499-503, 2005

SRef-ID: 1684-9981/nhess/2005-5-499

European Geosciences Union

(C) 2005 Author(s). This work is licensed

under a Creative Commons License.

\title{
Perception of intense precipitation events by public opinion
}

\author{
A. M. S. Delitala \\ Servizio Agrometeorologico Regionale per la Sardegna, Viale Porto Torres 119, I-07100 Sassari, Italy \\ Received: 29 March 2005 - Revised: 22 June 2005 - Accepted: 22 June 2005 - Published: 22 July 2005 \\ Part of Special Issue "HYDROPTIMET"
}

\begin{abstract}
A survey of four years of local newspapers over the island of Sardinia was conducted. Articles were compared against meteorological observations in order to understand how efficiently intense precipitation events are perceived.

The comparison showed that, on a wide and heterogeneous area, public opinion perceives correctly $44 \%$ of events and its perception is unbiased. If, however, the focus is placed upon urban areas, the ability to perceive grows to $66 \%$, but an "overperception" of $33 \%$ arises. If focus is finally placed upon rural areas, skills worsen, several events are missed and a significant negative bias is detected.
\end{abstract}

\section{Introduction}

Any analysis of intense precipitation events should first begin by defining what is meant by "intense". In a scientific contest, that would be done by trying to make the definition as objective as possible ${ }^{1}$. The average person, however, is usually led to define intensity in a subjective way. He would probably consider a precipitation event to be "intense" if it causes casualties, damages (and economic losses), or if it simply strikes imagination, so to appear somehow extraordinary.

The philosophical problem of how perception of intense events actually works has rarely been addressed by the meteorological community. An interesting example can be found in Downton and Pielke (2001) that analyzes flood-related disaster declaration by the President of the United States. One

Correspondence to: A. M. S. Delitala

(delitala@sar.sardegna.it)

${ }^{1}$ Even in the scientific community there is an open debate on how to define intense or even extreme events. An example of the debate can be found in: Speranza, A., Delitala, A. M. S., Deidda, R., Corsini, S., Monacelli, G., et al: Estremi nelle scienze ambientali. Sintesi del dibattito tenuto nel convegno Gli eventi estremi: alla ricerca di un paradigma scientifico condiviso, tenutosi ad Alghero (SS) il 24-26 Settembre 2003, in preparation, 2005. of the key issues highlighted by the authors is that the frequency and type of presidential declarations is somehow influenced by perception of disasters by public opinion.

An other interesting work is a very recent one by Palutikof et al. (2004), where the authors analyze direct perception of thermal extremes by public, by means of a survey conducted in the UK. Three key issues are examined in the paper: (a) direct experience of anomaly warm weather and reaction to it; (b) perception of events affecting the whole country; (c) perception of climate change.

On the other hand, a great deal of work has been done in trying to quantify the effects of intense or extreme events upon society, particularly from the economical and political point of view. Two examples are in Pielke and Downton (1999) and Pielke (2000) both dealing with societal damages, their trends and their connections to meteorological events.

Comparing subjective perception by public opinion against meteorological definitions can however be interesting, as well.

Recovering and organizing in an "objective" way, such a "subjective" information is obviously not easy. In the present analysis, e.g., it was decided to consider four years of articles published by three local newspapers and compare how many precipitation events, reported in the news as intense, could actually be define in that way by means of pluviometer observations.

It is clear that a journalist's perception is not necessarily an average person's perception and random circumstances will cause some significant events not be covered or minor events to be covered. It is true, however, that most of the times people do not directly experience intense precipitation events, so what they actually know and feel is what has been reported in newspaper or television. Moreover, even when direct experience exists, it is often biased by the point of observation, by what has been reported by others or, after sometimes, by confused memory of the episodes. An analysis based on all local newspapers of a region, then, would probably turn out to have a greater and more homogeneous sample than a survey of direct experiences. 
Table 1. Example of a dichotomous contingency table: $A$ counts how many events were observed and perceived as intense; $B$ counts perceived but not observed; $C$ counts observed but not perceived; $D$ counts events neither observed nor perceived as intense.

\begin{tabular}{|c|c|c|c|}
\hline & \multicolumn{2}{|c|}{ Observed } \\
\hline & & Intense & Not-Intense \\
\hline \multirow{2}{*}{ 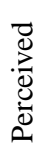 } & Intense & A & B \\
\hline & Not-intense & $\mathrm{C}$ & D \\
\hline
\end{tabular}

The choice of selecting local and regional news, rather than national or international ones, has two more advantages: in the first place, the typical journalist describes events closer to him/her so perceiving them in a way more similar to how someone directly affected by them would; secondly, since local news are usually organized to cover as many local events worth publishing as possible, they are likely to report almost any precipitation perceived as significant, so the random selection of news is reduced.

By reading articles more carefully, it becomes clear that what is actually felt as an "intense precipitation event" often (but not always) is a "strong surface runoff" caused by precipitation. What is missing in most of public opinion, then, is the ability to separate the meteorological phenomenon (the rainfall) and its hydrological effects.

Estimating surface runoff based on the available dataset is not an easy task, especially in the complex Sardinian basins. Moreover, it is not easy to precisely separate perception of meteorological and hydrological effects.

Introducing then the hydrological information would however lead beyond the scope of the present analysis and would not necessarily guarantee an improvement. Therefore it was decided not to separate the meteorological and the hydrological information, but to consider precipitation thresholds high enough to be typically associated to damages somewhere nearby.

\section{Scope of analysis and source of data}

The analysis was carried out in the island of Sardinia. The island is $22000 \mathrm{~km}^{2}$ wide and is in the center of Western Mediterranean. Population is about 1.5 million. Two urban areas exist, Sassari and Cagliari, populated by a few hundreds thousands people; the rest of the island is made of several small towns and wide rural areas.

From a climatic point of view Sardinia receives on average about $630 \mathrm{~mm} /$ year. It has a wet winter (October-April), accounting for $80 \%$ of the yearly precipitation, and a dry summer (May-September), during which time the influence of the Azores Anticyclone regime strongly reduces the penetration of Atlantic disturbances into the region or the formation of local disturbances (Delitala et al., 2000).
Extra-tropical cyclones, either due to primary Atlantic cyclogenesis or to secondary Mediterranean cyclogenesis (Speranza, 2001), cause most of precipitation. Intense events are not uncommon; a great deal of them are associated to convective cells fed by moist low level flows forced over steep orography.

More details on Sardinia climate and on mass fields typically associated to precipitation regimes can be found in Chessa \& Delitala (1996) and in Chessa et al. (1999).

The newspaper articles were published between September 1999 and August 2003 by all the three newspapers existing at that time in Sardinia: "La Nuova Sardegna", "L'Unione Sarda" and "Il Quotidiano". All articles describing events having taken places within Sardinia, somehow referable to intense precipitation, were considered.

Pluviometer observations come from 49 meteorological stations of SAR and from 8 more belonging to other institutions. This network homogeneously covers the island of Sardinia, although it is clear that some local intense precipitation may have been missed.

Overall, since Sardinia can be considered an heterogeneous region from a geographical point of view, its climate is quite typical of Mediterranean and the data are homogeneous and uniformly distributed over the territory, the present work can be considered a good proxy for an analysis of this type in a Mediterranean context.

\section{Analysis technique}

An event was considered to have been "perceived" as intense, if it had drawn the attention of at least one newspaper, i.e. if at least one article referring to it had been published. Any event covered by more than one article, even if published in more than one day, was considered as a single one.

A precipitation was "observed" to be intense if its total was higher than $50 \mathrm{~mm}$ or if it was part of a spell of five consecutive days whose totals added up to more than $100 \mathrm{~mm}$. Days belonging to both sets were taken only once.

In order to compare pluviometer observations against subjective perception, contingency tables were used (Wilks, 1995). Scores typically used in forecast verification of dichotomous phenomena were based upon such tables; "perceived values" were used instead of "forecast values", but names of skill scores were left as in the reference text.

Table 1 is an example of a contingency table. $A, B, C$ and $D$ represent the counts of the four possible pairs of perceived/observed events.

The percentage of correct perception is estimated by the "hit rate" (HR), defined as follows

$H R=\frac{A+D}{A+B+C+D}$.

This score is excellent when all four counts have the same magnitude. A perfect performance has $\mathrm{HR}=1$, i.e. $B=C=0$.

However, if $D \gg A+B+C$, HR tends to 1 , no matter how the performance was. In such cases, $D$ is trivial and must be 
Table 2. The full sample divided by classes of precipitation intensity.

\begin{tabular}{lrr}
\hline Threshold & Number of records & Number of days \\
\hline $\mathrm{P} \geq 0 \mathrm{~mm}$ & 77005 & 1461 \\
$\mathrm{P} \geq 1 \mathrm{~mm}$ & 14156 & 695 \\
$\mathrm{P} \geq 10 \mathrm{~mm}$ & 3539 & 349 \\
$\mathrm{P} \geq 50 \mathrm{~mm}$ & 80 & 32 \\
$\mathrm{P} \geq 100 \mathrm{~mm}$ & 11 & 7 \\
\hline
\end{tabular}

Table 3. Contingency table over the rainy days of the 1999-2003 period.

\begin{tabular}{|c|c|c|c|}
\hline & \multicolumn{2}{|c|}{ Observed } \\
\hline & & Intense & Not-Intense \\
\hline 7 & Intense & 17 & 12 \\
\hline $\begin{array}{l}\stackrel{0}{0} \\
\stackrel{0}{2}\end{array}$ & Not-intense & 14 & 627 \\
\hline
\end{tabular}

eliminated. A new score, called "threat score" (TS), is then defined as follows

$$
T S=\frac{A}{A+B+C} \text {. }
$$

By ignoring the "D counts", the threat score measures then the ability to perceive the rare event alone. As in the former case, the optimum is given by $\mathrm{TS}=1$.

The ability to actually perceive an event when it takes place is given by the "probability of detection" (POD), defined by

$$
P O D=\frac{A}{A+C} .
$$

The optimum is $\mathrm{POD}=1$ and it implies that $C=0$, i.e. that no intense event was missed. A similar score could be defined by using $B$ and $D$, when the latter is not a trivial case.

The percentage of mistakes made when events are perceived as intense is given by the "false alarm rate" (FAR), i.e.

$$
F A R=\frac{B}{A+B}
$$

It is clear that the optimum is FAR=0.

Finally the "bias" (BI) of perception in defined by

$$
B I=\frac{A+B}{A+C} .
$$

An unbiased performance has $\mathrm{BI}=1$. When $\mathrm{BI}>0$ there is a tendency to overperceive intense; the opposite happens when $\mathrm{BI}<1$.
Table 4. Skill scores over contingency table 3.

\begin{tabular}{lc}
\hline Type of score & Value \\
\hline Hit rate (HR) & 0.96 \\
Threat score (TS) & 0.40 \\
Probability of detection (POD) & 0.55 \\
False alarm rate (FAD) & 0.42 \\
Bias score (BI) & 0.94 \\
\hline
\end{tabular}

\section{Sample description, contingency tables and scores}

As it can be seen in Table 2, the sample is made of 77005 records of precipitation over Sardinia (distributed in 1461 days); most of the records refer to no rain or to trace of rain.

About one fifth of the records (distributed over 695 days) is made of "rainy days", i.e. days having totals $\geq 1 \mathrm{~mm}$, while 3539 records (distributed over 349 days) have totals $\geq 10 \mathrm{~mm}$. 80 records (distributed over 32 days) have precipitation over $50 \mathrm{~mm}$ and, finally, 11 events (on 7 days) are beyond $100 \mathrm{~mm} /$ day. "Events observed to be intense", then, belong to the 99th percentile of the record set and 95th percentile of the days under investigation.

The wide majority of the sample is made by dry days which are meaningless for the present analysis, so that it was decided to overlook them and only to consider days that were rainy at least over one station.

Table 3 shows the contingency table over the 695 rainy days. Despite the reduction of the sample, days neither observed nor perceived to be intense are still overwhelming., i.e., using notation of chapter $2, D \gg A+B+C$.

Skill scores based on Table 3 are shown in Table 4. Since "D counts" are overwhelming, HR is very high (0.96), but the result is trivial. If TS is used instead, the score decreases to 0.40 . As far as the other scores: POD is 0.55 , FAR is 0.42 and $\mathrm{BI}$ is 0.94 .

When the whole island is considered, the perception is then unbiased. Half of the events for observed intense rain had been perceived actually like intense ones (they have some repercussion in newspapers or public opinion) and the 42

It was then decided to separate perception on urban areas from perception in rural ones, in order to check whether it changes.

A sub-sample was then built, by selecting only days perceived or observed to be intense over the whole island (i.e. $A, B$ and $C$ "counts" of Table 3 ). On this sub-sample, events were considered to be "intense in cities" if they had been observed or perceived in the two urban areas, i.e. only when the cities of Cagliari and Sassari or their suburbs had been affected.

Tables 5 and 6 show contingency tables and scores based on the above sub-sample. HR is still high (0.88) and TS is higher than the former case (0.62); however "D counts" are not overwhelming anymore, so $\mathrm{HR}=0.88$ is a strong result. As far as the other skills, POD is 0.89 , FAD is 0.33 and BI 
Table 5. Contingency table over the sub-sample made of days either perceived or observed to be intense: focus upon urban areas.

\begin{tabular}{|c|c|c|c|}
\hline & \multicolumn{2}{|c|}{ Observed } \\
\hline & & $\begin{array}{l}\text { Intense } \\
\text { in cities }\end{array}$ & $\begin{array}{l}\text { Not-Intense } \\
\text { in cities }\end{array}$ \\
\hline \multirow{2}{*}{ 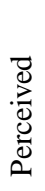 } & Intense & 8 & 4 \\
\hline & $\begin{array}{l}\text { Not-intense } \\
\text { in cities }\end{array}$ & 1 & 30 \\
\hline
\end{tabular}

Table 6. Skill scores over contingency table 5.

\begin{tabular}{ll}
\hline Type of score & Value \\
\hline Hit rate (HR) & 0.88 \\
Threat score (TS) & 0.62 \\
Probability of detection (POD) & 0.89 \\
False alarm rate (FAD) & 0.33 \\
Bias score (BI) & 1.33 \\
\hline
\end{tabular}

is 1.33 , meaning that an "overperception" of intense events occurs when cities are affected.

On the same sub-sample as above, perception over rural area was tested, by considering "intense in rural areas" those events not affecting the cities of Cagliari and Sassari and their suburbs. The analysis is somewhat noisier than above, since small towns (which are something in between a city and a real rural area) are included; moreover several events affected or were perceived as intense in urban areas as well, making it difficult to separate the two sets.

Tables 7 and 8 show contingency tables and scores using the new criterion. HR now decreases to 0.51 while TS is 0.40 . POD is $0.64, \mathrm{FAD}$ is 0.59 and a negative bias $(\mathrm{BI}=0.81)$ is observed. The values of POD and BI clearly show an "underperception".

Finally, if contingency Tables 3, 4 and 7 are compared, it is clear that 13 out of 14 events observed in the full sample but completely missed by perception ("C counts" in Table 3 ) actually belong in rural areas ("C counts" in Table 7).

\section{Comments and conclusions}

Over a wide and heterogeneous area like Sardinia, perception of intense events seems to be fairly skillful: perception is correct $40 \%$ of times. A little more than half of intense events are actually perceived $(\mathrm{POD}=0.55)$ and only about two fifth of perceived events turn out to be wrong (FAR=0.42). Finally, perception is not biased (BI=0.94).

If urban areas are focused upon, the skill rises (i.e. $\mathrm{HS}=0.62$ ) and the percentage of events correctly perceived almost reaches $90 \%(\mathrm{POD}=0.89)$. This is clearly due to the
Table 7. Contingency table over the sub-sample made of days either perceived or observed to be intense: focus upon rural areas.

\begin{tabular}{|c|c|c|c|}
\hline & \multicolumn{2}{|c|}{ Observed } \\
\hline & & $\begin{array}{c}\text { Intense } \\
\text { in rural areas }\end{array}$ & $\begin{array}{l}\text { Not-Intense } \\
\text { in rural areas }\end{array}$ \\
\hline Z & $\begin{array}{l}\text { Intense } \\
\text { in rural areas }\end{array}$ & 14 & 8 \\
\hline 2.0ّ & $\begin{array}{l}\text { Not-intense } \\
\text { in rural areas }\end{array}$ & 13 & 8 \\
\hline
\end{tabular}

Table 8. Skill scores over contingency table 7.

\begin{tabular}{lc}
\hline Type of score & Value \\
\hline Hit rate (HR) & 0.51 \\
Threat score (TS) & 0.40 \\
Probability of detection (POD) & 0.52 \\
False alarm rate (FAD) & 0.59 \\
Bias score (BI) & 0.81 \\
\hline
\end{tabular}

fact that in more populated area it is more likely that someone is hit by precipitation, eventually suffering damages. Perception is also more precise, since the percentage of "false alarms" decreases to one third $(\mathrm{FAD}=0.33)$. The higher attention paid to intense events causes a positive bias of about $33 \%$ (BI=1.33).

In rural areas, on the other way, perception is less skillful. Almost all overlooked events occurred there, so that POD drops to 0.52 , and the rate of "false alarms" grows to 0.59 . That happens because in rural areas intense events may often not affect people or may be far away from most of population so that perception is distorted. The balance of the two pushes towards "underpeception" and the bias is negative $(\mathrm{BI}=0.81)$.

Finally, despite the noise of both sources of information, results appear reasonable and encourage towards new studies.

Acknowledgements. The present research was funded under the Interreg III-B/MEDOCC project of the European Union.

The author would like to thank Roger Pielke jr for some interesting suggestions. The work of Francesca Manconi of SAR was also fundamental for the selection of newspaper articles.

The author would also like to thank Prof. Brett Brandon of the University of Sassari for reviewing the English form and the anonymous referees for their suggestions on how to improve the paper.

Edited by: M.-C. Llasat

Reviewed by: three referees 


\section{References}

Chessa, P. A. and Delitala, A. M. S.: Il Clima della Sardegna, SAR, Sassari (Italy), 1996.

Chessa, P. A., Cesari, D., and Delitala, A. M. S.: Regimes of Precipitation and Temperature in Sardinia (Italy) and the related synoptic situations, Theoretical and Applied Climatology, 63, 195222, 1999

Delitala, A. M. S., Cesari, D., and Chessa, P. A.: Precipitation regimes over Sardinia (Italy) during the 1946-1993 rainy season and associated large-scale climatic variations, International Journal of Climatology, 20, 519-542, 2000.

Downton, M. and Pielke Jr., R. A.: Discretion Without Accountability: Climate, Flood Damage and Presidential Politics, Natural Hazards Review, 2(4), 157-166, 2001.

Il Quotidiano, Piccola società cooperativa editrice del NordSardegna, Sassari (Italy), 1999-2003.

La Nuova Sardegna, Editoriale La Nuova Sardegna, Sassari (Italy), 1999-2003.
L'Unione Sarda, Editrice L'Unione Sarda, Cagliari (Italy), 1999_ 2003.

Palutikof, J. P., Agnew, M. D., and Hoar, M. R.: Public perception of unusually warm weather in the UK: impacts, responses and adaptation, Climate Research, 26, 43-59, 2004.

Pielke Jr., R. A.: Flood Impacts on Society: Damaging Floods as a Framework for Assessment, in: Floods, edited by: Parker, D., Routledge Press, London (UK), 133-155, 2000.

Pielke Jr., R. A. and Downton, M.: U.S. Trends in Streamflow and Precipitation: Using Societal Impact Data to Address an Apparent Paradox, Bulletin of the American Meteorological Society, 80(7), 1435-1436, 1999.

Speranza, A.: The physical mechanism of secondary cyclogenesis, Recent Research Development in Atmospheric Sciences, 1, 5768, 2000.

Wilks, D.: Statistical Methods in the Atmospheric Sciences: an Introduction, Academic Press, San Diego (USA), 1995. 